\title{
Why reduce health inequalities?
}

\author{
Alistair Woodward, Ichiro Kawachi
}

\begin{abstract}
It is well known that social, cultural and economic factors cause substantial inequalities in health. Should we strive to achieve a more even share of good health, beyond improving the average health status of the population? We examine four arguments for the reduction of health inequalities.

1 Inequalities are unfair.

Inequalities in health are undesirable to the extent that they are unfair, or unjust. Distinguishing between health inequalities and health inequities can be contentious. Our view is that inequalities become "unfair" when poor health is itself the consequence of an unjust distribution of the underlying social determinants of health (for example, unequal opportunities in education or employment).

2 Inequalities affect everyone.

Conditions that lead to marked health disparities are detrimental to all members of society. Some types of health inequalities have obvious spillover effects on the rest of society, for example, the spread of infectious diseases, the consequences of alcohol and drug misuse, or the occurrence of violence and crime.
\end{abstract}

3 Inequalities are avoidable.

Disparities in health are avoidable to the extent that they stem from identifiable policy options exercised by governments, such as tax policy, regulation of business and labour, welfare benefits and health care funding. It follows that health inequalities are, in principle, amenable to policy interventions. A government that cares about improving the health of the population ought therefore to incorporate considerations of the health impact of alternative options in its policy setting process.

3 Interventions to reduce health inequalities are cost effective.

Department of Public

Health, Wellington

School of Medicine,

PO Box 7343

Wellington South, New

Zealand

A Woodward

Department of Health and Social Behavior, Harvard School of Public Health, Boston, USA

I Kawachi

Correspondence to: Professor Woodward (woodward@wnmeds.ac.nz)

Accepted for publication 12 July 2000 that reducing inequalities will diminish "spill over" effects on the health of society at large. In principle, you would expect that differences in health status that are not biologically determined are avoidable. However, the mechanisms giving rise to inequalities are still imperfectly understood, and evidence remains to be gathered on the effectiveness of interventions to reduce such inequalities.

(F Epidemiol Community Health 2000;54:923-929)

It is well known that good health is not evenly shared. For example, according to the UK Independent Inquiry into Inequalities in Health, if all men aged 20-64 had the same mortality rates as those in the top two social classes, there would be approximately 17000 fewer deaths each year in that country. ${ }^{1}$

Many would agree that inequalities such as these are undesirable, but we seldom spend time examining the reasons why we should attempt to reduce them. (In this paper we are concerned primarily with inequalities that are attributable to social, economic and cultural causes. However, the same arguments apply to all variations in health that are not determined entirely by biological differences.) Simply documenting the presence of these inequalities is not sufficient to justify spending money to smooth the curve. Policies to reduce differences in health status may be expensive, and require sustained commitment to bring about change. On occasion, these policies may conflict with interventions that would achieve the greatest health gain for the population overall. It would seem important, for all these reasons, to ask why health inequalities should be reduced.

We examine four arguments for taking action, based on those outlined by Benzeval et $a .^{2}$ The arguments are of different kinds, including consideration of societal values such as "fairness" as well as more instrumental considerations such as "spillover" effects, disease reduction and cost effectiveness. Some of the arguments overlap and our list is by no means definitive. We offer our views on the weight of the different arguments, but the main purpose of the paper is to further discussion, especially in the light of recent debates about whether the reduction of poverty (and associated illnesses) should be a part of the mission of epidemiology. ${ }^{3}$ We draw many examples from New Zealand, which through the 1980s and 1990s experienced the fastest increase in income inequality of any OECD country. ${ }^{5}$ In New Zealand there are also large differences in health between indigenous (Maori) and nonindigenous peoples, explained largely but not 
entirely by variations in social and economic factors such as income, education and employment. ${ }^{6}$

\section{The four arguments}

1 INEQUALITIES ARE UNFAIR

Fairness is not the same as equality. For example, people vary in their eye colour and blood type, but these differences are scarcely unfair or unjust. The question of which inequalities are unfair has been keenly debated for a long time, and we do not attempt to repeat the substantial philosophical analyses that are presented elsewhere, ${ }^{78}$ but instead draw attention to some of the complexities and uncertainties that balance the intuitive appeal of this line of argument.

One might argue that we should seek equality on the grounds that "men and women should enjoy equal satisfaction of certain basic, common needs and rights". ${ }^{9}$ But how does this apply to health?

There is a distinction between achieved health status and opportunities for good health. If everyone has a similar chance to live healthily, is it unfair if health status varies? One could make a case that when people are responsible for actions that lead to loss of health, then the resulting inequality in health status cannot be described as unfair. This approach has a number of attractions. It emphasises differences in health status that can be remedied, and acknowledges that people carry a responsibility for their health. It implies that we should concentrate on reducing inequalities in health for which the people who suffer them clearly have little or no responsibility.

However, there are different views on the extent to which people can be held responsible for their actions. For example, smoking is a habit with serious consequences for health. Is this risk freely chosen? Whether or not a person chooses to smoke tobacco is a consequence of both the environment (role models, availability of cigarettes, price, tobacco promotion, health education, etc) and personal preference, but the extent of free choice is debatable. Most smokers take up the habit while adolescents, at an age when people have a limited capacity to make truly free choices. ${ }^{10}$ Furthermore, the addictive nature of nicotine means that one might question the limits of "personal choice" of smokers, of any age, to give up the habit. ${ }^{11}$ Exposure to environmental tobacco smoke (passive smoking), which carries some of the risks associated with active smoking, is almost entirely involuntary.

Achieving equity might be translated as eliminating disadvantage attributable to factors beyond the person's control. In a wider sense, these factors include significant past events. For example, in New Zealand the poor health of Maori is linked to the history of colonisation in the 1800 s and 1900s. Far reaching causes of ill health included the alienation of land and suppression of Maori culture and language. ${ }^{6}$ One could argue that the present health gap between Maori and non-Maori is an equity issue because these powerful, historical predisposing factors lie outside the control of the people who now experience an excess of disease and injury. In any event, there is no doubt that health is more than a matter of personal choice: the decisions that people make about health are shaped by the environment in which they are conceived, raised and live their adult lives. There are many instances in which personal responsibility plays a very small part, by anyone's account. Inequalities in health in childhood are one example, and so is ill health in adult life that is wholly or largely caused by experiences in childhood.

Different philosophical arguments have been advanced for strategies to improve population health. For example, it is possible that a utilitarian philosophical position might be comfortable with an improvement in average health status that does not necessarily result in a narrowing of differentials by socioeconomic status. So long as health gains are maximised ("the greatest good for the greatest number"), a person hewing to such a position would express few reservations about policies that widened health differentials. A different philosophical position might view health as such an important asset (both as an end in itself, as well as an instrumental ingredient in achieving valued "doings and beings") that gross inequalities in its distribution would be regarded as intrinsically problematic. ${ }^{12}$ In this light, poor health is one of the most important causes of restricted opportunity and limited personal freedom. More recently, Daniels and colleagues $^{13}$ have cast the problem of health inequalities within a Rawlsian framework, arguing that socioeconomic disparities in health status are unfair to the extent that they reflect underlying inequities in the distribution of "primary goods" - that is, the social determinants of health, including liberty, powers, opportunities, income and wealth, and the social bases of self respect.

The "inequalities are unfair" argument is emotionally compelling. For many, it is simply an affront to their sense of what is fair and proper that some people should have more than their share of avoidable illness. However, when challenged, most of us probably find it difficult to explain why such a situation should be unacceptable. There is, as yet, no complete account of justice that describes which health differences are unjust, or that prescribes exactly the extent to which they should be reduced. As Marchand et al observe, "although the serious injustice of these inequalities [in health] may be apparent, the precise nature of the injustice is not."

\section{INEQUALITIES AFFECT EVERYONE}

This line of argument emphasises that a reduction in health inequalities would bring benefit to others in the population besides those with the worst health. There is evidence to support this view from the history of public health: one reason the sanitary reforms of the 19th century took place was that the affluent realised that the living conditions of the poor were a threat to their own good health. Cholera, tuberculosis and other epidemics of the time freely crossed geographical and social boundaries. ${ }^{14}$ We see 
the same picture with modern epidemics such as AIDS, where disease emerges in conditions of poverty and disorder but is not confined to these populations. Indeed the potential for spread is even greater than it was a 100 years ago. ${ }^{15}$

Self interest applies not only to control of infectious disease: alcohol misuse, mental illness and violence also illustrate the general principle that everyone may be affected by the conditions of the weakest and most vulnerable members of their community. The argument for reducing health inequalities to contain "spill over" may be applied to the underlying social inequalities themselves. Economic inequalities, for example, were shown in the United States to be closely related to the frequency of deaths from external causes (homicides and accidents). ${ }^{16}$ By way of explanation, it has been proposed that wide differentials in income promote exclusion, lower thresholds for risk and violence, and weaken the social connections that make for healthy communities. ${ }^{17}$

Another strand to this argument is the claim that interventions to reduce social inequalities will have other benefits than improvements in health. For example, investment in better housing may result not only in less respiratory disease and fewer house fires, but may lead also to less strain and violence in families, with consequent benefits to all members of society. It has been suggested that loss of the "social glue" that holds groups together may have many adverse consequences, including latent social conflict, diminished functioning of democracy, and reduced investment in social goods such as education and health care. ${ }^{18}{ }^{19}$ In the US, wide inequalities in income at the state level tend to go along with lower than average expenditure in human capital (for example through spending on public education), and this is reflected in outcomes such as lower literacy and higher school drop out rates that will ultimately disadvantage society as a whole. ${ }^{20}$

When there are marked inequalities, those who are disadvantaged may lack the resources to participate in the social and economic mainstream of society. The same is true in relations between countries: wide disparities of wealth and power mean that poorer nations are effectively excluded from international affairs. Apart from moral considerations, exclusion is costly. Exclusion is inefficient (as it represents a loss of potential resources) and unsafe (individuals and countries that are out of the mainstream do not have a stake in national and international security).

The historian David Landes has written:

"Some countries are not only not gaining [on the rich], they are growing poorer, relatively and sometimes absolutely. Others are barely holding their own. Others are catching up. Our task (the rich countries), in our own interest as well as theirs, is to help the poor become healthier and wealthier. If we do not, they will seek to take what they cannot make; and if they cannot earn by exporting commodities, they will export people. In short, wealth is an irresistible magnet; and poverty is a potentially raging contaminant; it cannot be segregated, and our peace and prosperity depend in the long run on the well-being of others." (page $\mathrm{xx})^{21}$

In summary, health is an exquisitely sensitive mirror of social circumstances. With some causes of illness (such as infectious disease) it is plain that interventions to reduce inequalities by improving the health of the most disadvantaged will benefit all members of society. "Spill over" effects are not so evident with other conditions such as coronary heart disease. However, there is a growing body of research that suggests reducing the social and economic inequalities that lie behind the uneven distribution of disease will bring a wide range of benefits.

3 INEQUALITIES ARE LARGELY AVOIDABLE

In theory, inequalities could be reduced by "levelling down" the health of the groups at the top of the distribution. However, we would phrase the "avoidability" argument differently. It is, essentially, that inequalities in health can be reduced without diminishing the health of the population overall.

Is there evidence that this ideal state of affairs can be achieved? After all, inequalities in life expectancy have remained unchanged, or have even widened in recent decades in many countries, including New Zealand ${ }^{22}{ }^{23}$; the $\mathrm{UK}^{24}$; and the USA. ${ }^{25}$ Some public health efforts targeted at modifying individual lifestyles may have actually worsened health disparities in recent decades. While important gains have been made in areas such as smoking cessation and prevention of infectious disease, change has often occurred most rapidly among groups that already have better than average health status. ${ }^{26}{ }^{27}$ If the affluent adopt healthier lifestyles faster than the less well off, the net result of individually targeted intervention is increased disparity in outcomes.

Are wider inequalities an inevitable price we pay for better population health overall? Is it true that "a high waged, highly educated, highly skilled, economically expanding and predominantly middle-class society is good for the national health - despite its accidental promotion of inequality" ${ }^{\prime 28}$ ? The answer is no (in our view). Disparities in health are not a natural or inevitable consequence of a wealthier society, and effective interventions to improve health need not lead to greater inequalities.

Firstly, widening inequalities are not a necessary outcome of a "high waged, highly educated, economically expanding society". A number of countries (Denmark and Norway are two examples) that have achieved economic growth in recent decades have done so while protecting the position of the most disadvantaged groups in their societies. Economic inequalities are not accidental: they result from decisions made by society on issues such as tax policy, home ownership, business regulation, welfare benefits and health care funding. ${ }^{29} 30$

Secondly, it is patently not true that everybody is better off in a society that is "economically expanding and predominantly middle class [and increasingly unequal]". In the 
UK the economic reforms of the later Thatcher years were followed by a rise in death rates in the most disadvantaged groups. ${ }^{31}$ In New Zealand, death rates in non-Maori in middle age (30-79 years) have steadily fallen since the introduction of the free market reforms of the 1980s. Analyses of recent trends are complicated by changes in the coding of ethnicity in vital statistics, but it seems that mortality rates in Maori have not improved, and may actually have worsened. (New Zealand Health Information Service, unpublished data). This lack of improvement in the circumstances of the most vulnerable groups (measured in absolute terms) is apparent also in economic measures: a review of data from the national Household Expenditure Survey shows that between March 1981 and March 1994 the real disposable income of the top $20 \%$ of New Zealand wage and salary earners rose by $8.6 \%$, but the income of the lowest $20 \%$ fell by $7.5 \% .^{32}$

Finally, while some forms of public health interventions may result in a widening of health inequalities, this is by no means inevitable. The distribution of effects depends on the nature of the intervention-structural and environmental interventions are likely to affect the population more evenly than educational programmes aimed at individual behaviour change (and also have greater potential to reduce health inequalities). For example, fluoridated water supplies have been most beneficial for children with the highest rates of tooth decay, and consequently the addition of fluoride to drinking water has reduced dental health inequalities. ${ }^{33-35}$ Similarly, tax changes to raise the price of cigarettes have lowered smoking rates most in the groups with the highest consumption. ${ }^{36}$

There have been periods in the past when there have been deliberate moves to reduce inequalities in incomes and access to social services and there has been simultaneously a greater than expected improvement in the health of the population. Examples include Britain during the second world war, ${ }^{37}$ and Japan in the 1960s and 1970s. ${ }^{38}$ It is not certain whether such policies can be translated readily to other countries and different time periods. In New Zealand the sharpest reduction in Maori-non-Maori mortality differences occurred between the 1940s and the 1960s, a time of heavy investment in public services, and a period in which life expectancy for the population overall rose steadily. ${ }^{39}$ On the other hand, evidence from Europe indicates that in recent times there has been only a weak association at a national level between income inequalities and inequalities in health. For example, mortality differentials in Scandinavian countries widened rapidly in the 1970s, approximately a decade before income inequalities in these countries began to increase. ${ }^{40}$

"High risk" strategies of prevention seem well suited to reducing health inequalities, as they aim to identify and treat people belonging to the tail of the population distribution of risk factors (for example, screening and control of high blood pressure). ${ }^{41}$ The major problem with this approach is that although a relatively small number of people at high risk of disease may benefit, the health status of the population overall changes little. ${ }^{2}$ In contrast, the "population" strategy, which seeks to shift the entire distribution of risk in a favourable direction, rather than truncating the most abnormal segment of the distribution, has greater potential to improve health status overall. But such interventions will not change health differentials unless they also reduce the spread of risk. It was appreciated relatively early in road safety, for example, that it was more effective to change the environment of the road user than to rely on the road user to change his or her behaviour. $^{42}$ Crash padding, seat belts and safety glass are all effective population-wide strategies. In principle, these interventions offer equal protection to all although in practice the benefits are not distributed absolutely evenly. For example, expensive cars tend to offer more effective crash protection than cheaper vehicles, and seat belts reduce severity of injury more in low speed urban crashes than high speed rural crashes.

In summary, we do not know if health inequalities can be eliminated altogether, but there is evidence that they can be reduced. We know that public health interventions often do maintain inequalities, or even cause them to increase, because of differential uptake of new information and technology. But there is no reason to believe a priori that this is inevitable: if governments' social and economic policies can widen health inequalities, then it is plausible that different policies could reduce them.

4 COST EFFECTIVE INTERVENTIONS EXIST

This line of argument maintains that reducing inequalities will lead to larger gains in health status than might be achieved by similar expenditures elsewhere.

There are two major obstacles to making judgments about the cost effectiveness of interventions to reduce socioeconomic disparities in health: (a) paucity of evidence on effectiveness and cost; and (b) incomplete understanding of mechanisms underlying socioeconomic disparities in health, and hence, imperfect knowledge about what approaches should be adopted.

Few preventive interventions in public health have been designed with the explicit goal of reducing socioeconomic disparities in health. ${ }^{43}$ For example, strategies to reduce smoking, increased cholesterol, and high blood pressure, have been designed to achieve overall reduction in these risk factors. But any preventive strategy that relies on access to the health care system for delivery - such as the detection of high cholesterol and blood pressure-may worsen socioeconomic gradients in outcomes (such as stroke, heart disease) if there are disparities in access to primary care.

Interventions that focus on improving access to health care for disadvantaged groups may reduce socioeconomic inequalities in health status, but few controlled studies have been carried out. ${ }^{44}$ One exception is the Health Insurance Experiment in the US that randomly assigned 3958 people aged 14 to 61 to a set of 
insurance plans for three to five years. ${ }^{45}$ One plan provided free health care; the others required enrollees to pay a share of their medical bills. As expected, patients in the latter group made approximately one third fewer visits to a physician and were hospitalised one third less often. Although the trial lacked statistical power to detect significant differences between groups in major health outcomes, the results none the less suggested that free care resulted in lower levels of major risk factors (such as hypertension) and better health status. Of note, the greatest benefits of free health care were seen among patients with the highest risk factor profiles (the upper quintile of the distribution of risk factors)

On the basis of the results of the Health Insurance Experiment, Woolhandler and Himmelstein ${ }^{46}$ estimated that between 47000 and 106000 lives would be saved annually in the US as a result of providing free, universal health care in that country. In other words, improving access to health care could produce a potentially substantial benefit in terms of reducing socioeconomic disparities in health.

But the major limitation of interventions aimed at improving access is that health care delivery explains only a portion (albeit an important part) of the socioeconomic gradient in health. ${ }^{47}$ Medical technology, however efficacious, is unlikely to break the link between socioeconomic conditions and health outcomes. For example, neonatal intensive care units may have been an important contributor to reducing black/white disparities in infant mortality within the United States but black/white disparities in infant mortality persist, and intensive care units have had no impact on racial disparities in the frequency of low birth weight - which presumably reflect exposures to upstream social conditions. In principle, one would expect interventions outside the health sector that influenced basic health determinants such as income, employment and education to have the greatest effect on inequalities. However, at present, evidence of effectiveness is best at the level of health sector programmes. ${ }^{44}$ There are perhaps two reasons for this: the health impacts of broader economic and social policies are seldom assessed; and, it is very difficult to quantify accurately the health improvements that can be attributed to a specific policy. ${ }^{48}$

On the other hand, there are theoretical grounds on which to recommend that the health care system could do more to reduce socioeconomic disparities. An example can be found in the case of Pap screening for cervical cancer. $^{49}$ If $54 \%$ of the women who are currently annually screened in the United States were to be switched to a schedule of screening every three years, these women would require 30 fewer tests each between the ages 20 to 65 . The protection against cervical cancer among these women would decrease only slightly, from $93.5 \%$ to $90.8 \%$. By allocating the saved resources to ensure that the $22 \%$ of the population previously screened every 10 years is now screened every three years, we could expect a substantial gain in their protection from cervical cancer (from $64 \%$ to
KEY POINTS

- The reasons for reducing health inequalities warrant scrutiny.

- The most powerful argument for reducing health inequalities is on the grounds of justice, although theories of justice do not guide us on how much to reduce inequalities.

- The bulk of health inequalities are in principle avoidable, though we often lack data on the effectiveness and cost of interventions.

- In certain cases, reducing health inequalities will benefit society at large by reducing the incidence of spillover effects.

$90.8 \%$ ), while increasing their lifetime Pap smears from 5 to 15 . At the population level, this strategy translates into fewer cases of cervical cancer (an overall $4.4 \%$ reduction), and about half the current number of Pap smears (from 29 to 15 tests per woman).

In summary, re-allocating resources to target socioeconomic disparities could result in lower costs and greater marginal benefit. Whether resources freed up in this way could be successfully deployed to increase coverage is another issue - these estimates assume full follow up and treatment of lesions among all participants. None the less, the Pap smear example does suggest that the goal of increased equity need not be incompatible with the goal of maximising efficiency.

Our imperfect understanding of the mechanisms of socioeconomic gradients limits our ability to formally evaluate the cost effectiveness of interventions designed to reduce such disparities. The "fundamental causes" that determine the distribution of "down stream" disease risk factors in the population include variables such as the unequal distribution of knowledge, money, power, prestige, and social connections. ${ }^{50}$ Intervening at this level widens the base of health care policy into the realms of social and economic policies-such as income redistribution, housing policy, urban planning.

Measured against the kinds of interventions that we currently pursue in public health (such as the detection and treatment of hypertension), the potential benefits of reducing socioeconomic gradients in health are substantial. For example, the absolute risks and risk differences across categories of income level in mortality are as great as, or greater than those observed in untreated mild to moderate hypertension. Of course, we are assuming that raising someone's income will reap the full benefit of the risk difference reported between income categories - an assumption that may not be borne out; we simply lack the evidence.

The failure of economists and policymakers to incorporate an explicit consideration of the population health impact of their choices may partly explain why little progress has been made in reducing health disparities despite decades of evidence documenting their existence. For too long, politicians have assumed (or been advised) that health disparities are 
amenable to interventions in the health sector alone, whereas the bulk of evidence on the population determinants of health points to the need to intervene in broader social sectors (for example, labour policy, housing, income maintenance). In other words, we see a role for public health professionals to reach outside their field to inform society of the health consequences of choices in social policy.

\section{Conclusion}

In this paper we have reviewed four arguments for the reduction of health inequalities attributable to economic, social, and cultural factors.

Socioeconomic inequalities potentially affect every member of society via spillover effects. An obvious example is the rate of crime and violence: large disparities in social rewards (income and wealth) produce higher rates of property crime and violence. Spillover effects have been documented for many other social ills, including infectious disease (AIDS and tuberculosis) and drug misuse. A society that tolerates a steep socioeconomic gradient in health outcomes will experience a drag on improvements in life expectancy, and pay the cost via excess health care utilisation.

Are inequalities in health avoidable? People differ in many respects, including economic resources, political power, cultural assets and health status. While some types of assets are amenable to redistribution, others (such as "inborn talent") may not be, and the extent of redistribution is a matter of social preference. However, there are many opportunities to achieve greater equity in health-for example, by investment in human capital, redistributive policies (such as income maintenance and family support), and ensuring comprehensive access to health care.

Both theory and evidence suggest that the size of the gains that might be made by reducing inequalities is impressive. For example, in New Zealand, cancer deaths attributable to smoking would be reduced by about $70 \%$ if the rate in the most socially advantaged group applied across the whole population. There are public health programmes that reduce inequalities and are demonstrably cost effective (fluoridation of water is one example), but on the whole we still know relatively little about the costs and relative effectiveness of interventions to reduce inequalities in health.

The "lack of fairness" argument has strong intuitive appeal, and in our view is likely to be the most influential. It may be difficult to be specific about the nature of the injustice, but the case for intervening is most compelling where the issue of personal responsibility is least relevant (with child health, for example).

We acknowledge the assistance we received from Johan Mackenbach, Ashley Bloomfield and colleagues who reviewed the report to the NHC.

Funding: this work was funded by the National Health Committee of New Zealand, and appeared in an earlier form as a special report to the Committee (Woodward A, Kawachi I. Why should we reduce inequalities? National Health ComWhy should we reduce inequalities? National Health Committee: Health Determinants Programme Backgroun

Conflicts of interest: none.
1 Report of the Independent Inquiry into Inequalities in Health. London: Stationery Office, 1998.

2 Benzeval M, Judge K, Whitehead M, eds. Tackling inequalities in health: an agenda for action. London: King's Fund, 1995.

3 Rothman KJ, Adami H-O, Trichopoulos D. Should the mission of epidemiology include the eradication of poverty? Lancet 1998;352:810-12.

$4 \mathrm{McMichael}$ AJ. The role of epidemiologists in eradicability of poverty. [Letter]. Lancet 1998;352:1627.

5 Hills J. A summary of the evidence: Foseph Rowntree Inquiry into Income and Wealth. Volume 2. York: Rowntree Foundation, 1995.

6 Durie M. Waiora. Maori health development. Auckland: Oxford University Press, 1994

7 Stronks K, Gunning-Schepers LJ. Should equity in health be target number 1? Eur f Public Health 1993; 3:104-11.

8 Marchand S, Wikler D, Landesman B. Class, health and justice. Milbank $Q$ 1998; 76:449-67.

9 Bullock A, Stallybrass O, eds. The Fontana dictionary of modern thought. London: Fontana/Collins, 1977.

10 Winstanley M, Woodward S, Walker N. Tobacco in Australia. Facts and issues 1995. Melbourne: Victoria Smoking and Health Programme, 1995.

11 US Surgeon General. The health consequences of smoking. Nicotine addiction. Rockville, MA: US Department of Health and Human Services, 1988.

12 Sen A. Inequality re-examined. Cambridge, MA: Harvard University Press, 1992

13 Daniels N, Kennedy BP, Kawachi I. Why justice is good for our health: the social determinants of health inequalities. Daedalus 1999;128:215-51

14 Wohl AS. Endangered lives. Public health in Victorian Britain. Cambridge, MA: Harvard University Press, 1983.

15 Wallace R, Wallace D. Community marginalisation and the diffusion of disease and disorder in the United States. BMF 1997; 314:1341-5.

16 Wilson $M$, Daly M. Life expectancy, economic inequality, homicide, and reproductive timing in Chicago neighbourhoods. BMF 1997;314:1271-4.

17 Wilkinson RG, Kawachi I, Kennedy BP. Mortality, the social environment, crime and violence. Sociology of Health and Illness 1998;20:578-97.

18 Putnam RD. Making democracy work. Civic traditions in modern Italy. Princeton: Princeton University Press, 1993.

19 Kawachi I, Kennedy BP. Health and social cohesion: why care about income inequality? BMf 1997;314:1037-40.

20 Kaplan G, Pamuk E, Lynch JW, et al. Inequality in income and mortality in the United States: analysis of mortality and potential pathways. BMF 1996;312:1004-7.

21 Landes DS. The wealth and poverty of nations. New York: WW Norton, 1998.

22 Kawachi I, Marshall S, Pearce N. Social class inequalities in the decline of coronary heart disease among New Zealand men, 1975-1977 to 1985-1987. Int f Epidemiol 1991;20: 393-8.

23 Marshall SW, Kawachi I, Pearce NE, et al. Social class differences in mortality from diseases amenable to medical intervention in New Zealand men aged 15-64, 1985-1987. Int f Epidemiol 1993;22:255-61.

24 Marmot MG, McDowell ME. Mortality decline and widening social inequalities. Lancet 1986;ii:274-6.

25 Pappas G, Queen S, Hadden W, et al. The increasing disparity in mortality between socioeconomic groups in the United States, 1960 and 1986. N Engl f Med 1993;329. 103-9.

26 Hart N. Inequalities in health: the individual versus the environment. Fournal of the Royal Statistical Society Series A 1986;149:228-46.

27 Reading R, Colver A, Openshaw S, et al. Do interventions that improve immunisation uptake also reduce social that improve immunisation uptake also reduc

28 Charlton BG. Is inequality bad for the national health? Lancet 1994;343:221-2.

29 Fischer CS, Hout M, Jankowski M, et al. Inequality by design. Cracking the bell curve myth. Princeton: Princeton University Press, 1996.

30 Galbraith JK. Created unequal. The crisis in American pay. New York: The Free Press, 1998

31 Phillimore P, Beattie A, Townsend P. Widening inequality of health in northern England, 1981-91. BMF 1994;308: $1125-8$.

32 Statistics New Zealand. Incomes. Wellington: Statistics New Zealand, 1999.

33 Carmichael CL, Rugg-Gunn AJ, Ferrell RS. The relationship between fluoridation, social class and caries experiship between fluoridation, social class and caries experiland in 1987. Br Dent f 1989;167:57-61.

34 Treasure ET, Dever JG. The prevalence of caries in 5 -year-old children living in fluoridated and nonfluoridated communities in New Zealand. NZ Dental $\mathcal{F}$ 1991;88:9-13.

35 Riley JC, Lennon MA, Ellwood RP. The effect of water fluoridation and social inequalities on dental caries in 5-year-old children. Int f Epidemiol 1999;28:300-5.

36 Townsend J, Roderick P, Cooper J. Cigarette smoking by socioeconomic group, sex and age: effects of price, income and health publicity. BMF 1994;309:923-7.

37 Titmuss RM. Problems of social policy. History of the second world war. United Kingdom Civil Series. London: HMSO, 1950 .

38 Marmot MG, Davey Smith G. Why are the Japanese living longer? BMF 1989;299:1547-51. 
39 Pool I. Cross-comparative perspectives on New Zealand's health. In Spicer J, Trlin A, Walton J, eds. Social dimensions
of health and disease. New Zealand perspectives. Palmerston of health and disease. New Zealand perspe
North: Dunmore Press, 1994:16-50.

40 Martikainen P, Valkonen T. Policies to reduce income inequalities are unlikely to eradicate inequalities in mortality. BMF 1999;319:319

41 Rose G. Sick individuals and sick populations. Int $\mathcal{f}$ Epidemiol 1985;14:32-8.

42 Nader R. Unsafe at any speed. The designed in dangers of the American automobile. New York: Grossman Publishers, 1965.

43 Mackenbach JP, Gunning-Schepers LJ. How should interventions to reduce inequalities in health be evaluated? $f$ Epidemiol Community Health 1997;51:359-64.

44 Gepkens A, Gunning-Schepers LJ. Interventions to reduce socioeconomic health differences. Eur $f$ Public Health 1996;6:218-26.
45 Brook RH, Ware JE Jr, Rogers WH, et al. Does free care improve adults' health? Results from a randomised controlimprove adults' health? Results from a rand

46 Woolhandler S, Himmelstein DU. Free care: a quantitative analysis of health and cost effects of a National Health Program for the United States. Int $\mathcal{F}$ Health Services 1988;18:393-9

47 Adler NE, Boyce T, Chesney M, et al. Socioeconomic inequalities in health: no easy solution. $\mathscr{F} A M A$ 1993;269:3140-5.

48 National Health Committee. The social, cultural and economic determinants of health in New Zealand: action to improve health. Wellington, New Zealand: National Health Committee, 1998

49 Colditz GA, Hoaglin DC, Berkey CS. Cancer incidence and mortality: the priority of screening frequency and population coverage. Milbank $Q$ 1997;75:147-73.

50 Link BG, Phelan JC. Understanding sociodemographic differences in health - the role of fundamental social causes. Am f Public Health 1996;86:471-3. 